\title{
Arteriovenous Malformations of the Uterus: A Case Report and Review and Update of the Literature
}

Emad Bakir ${ }^{*}$, Anthony Kodzo-Grey Venyo ${ }^{2 *}$, Fatima M.Khafaji ${ }^{1}$, Rowaa Isam Eldin Seidahmed Mohamed ${ }^{1}$, Saad Ur Rehman ${ }^{1}$, Adham Darweesh $^{1}$

${ }^{1}$ Department of Radiology, Hamad Medical Corporation, Doha, Qatar.

2 North Manchester General Hospital, Department of Urology, Manchester M8 5RB. United Kingdom.

*Corresponding Author: Emad Bakir, Department of Radiology, Hamad Medical Corporation, Doha, Qatar.

Anthony Kodzo-Grey Venyo. North Manchester General Hospital, M8 5RB. Manchester United Kingdom

Received date: June 12, 2021; Accepted date: June 25, 2021; Published date: June 28, 2021

Citation: E Bakir, A K-G Venyo, F M.Khafaji, R I E S Mohamed, S U Rehman, A Darweesh. (2021) Structural heart disease interventions. Clinical Research and Clinical Trials. 4(1); DOI: 10.31579/2693-4779/050

Copyright: (c) 2021 Anthony Kodzo-Grey Venyo. This is an open access article distributed under the Creative Commons Attribution License, which permits unrestricted use, distribution, and reproduction in any medium, provided the original work is properly cited.

\begin{abstract}
Arteriovenous malformation of the uterus (AVMU) is a terminology that is used for an abnormal and non-functional connections between the uterine arteries and uterine veins. Even though patients who have AVMU typically tend to manifest with vaginal bleeding, some patients tend to experience life-threatening massive bleeding in some circumstances. Cases of AVMU had previously been safely and effectively treated by means of hysterectomy which meant that the patients would no longer have the ability to conceive and have their own babies in the future. Less than 100 cases of AVMU have been reported in the literature. Recently a minimal invasive procedure of Uterine Artery Embolization has been utilized to safely and effectively treat some patients who had AVMU that was associated with severe bleeding that led to cessation of their bleeding and associated symptoms as well as which enabled the patients to maintain their fertility. We report the case of a 27 -year-old woman. Gravida 1 . Para 0 , who was known to have irregular menstrual periods pursuant to her per vaginal passage of conception products. She was diagnosed as having AVMU based upon various radiology imaging options including: ultrasound scan of the pelvis; magnetic resonance imaging of the pelvis, and percutaneous left anterior internal iliac angiography. The AVMU was safely and effectively treated by means of percutaneous interventional radiology embolization of the AVMU and the final angiogram demonstrated satisfactory embolization which led to cessation of her vaginal bleeding and subsequently her retained products of conception were evacuated completely. As a result of the successful embolization of her AVMU, hysterectomy which was the alternative treatment option that was discussed, her uterus has remained intact which has given her the chance to be pregnant again in the future which would enable her have her own child. Considering that less than 100 cases of AVMUs have been reported in the literature, there is the chance that some clinicians may not be familiar with the manifestation, diagnosis, and management of AVMUs, in view of this we have also included miscellaneous narrations and discussions related to some case reports, case series, and studies related to AVMUs. Considering that there are few well-trained interventional radiologists globally as well as few interventional radiology units globally with fewer unts in the developing countries, we would recommend that more interventional radiologists should be trained globally and more interventional radiology units should be established globally especially in the developing countries.
\end{abstract}

Key Words: arteriovenous malformation; uterus; vaginal bleeding; miscarriage; ultrasound scan; pregnancy; product of conception; myometrium; colour doppler ultrasound scan; computed tomography scan; magnetic resonance imaging scan; selective angiography; super-selective embolization; hysterectomy; fertility

\section{Introduction}

Arteriovenous malformation of the uterus (AVMU) is a terminology that is utilized for an abnormal as well as non-functional connections that develop between the uterine arteries and uterine veins [1]. It has been iterated that arteriovenous malformations of the uterus (AVMUs) can be congenital AVMU lesions or they could be acquired AVMU lesions [1].
It has also been stated that congenital AVMUs are very uncommon conditions that tend to be reported sporadically; whereas, the incidence rate of acquired AVMUs has currently been increasing [2,3,4]. It may be argued that the current increase in the incidence of acquired AVMUs does relate to improvements and developments in radiology imaging globally including in routine ultrasound scanning, Doppler ultrasound scanning, 
contrast-enhanced computed tomography (CECT) scanning, contrastenhanced magnetic resonance imaging (CE-MRI) scanning, as well as in interventional radiology imaging facilities and in the number of welltrained interventional radiologists, especially in the developed world and parts of the well-resourced radiology departments of some of the developing countries. It has been iterated that acquired AVMUs often tend to be associated with previous surgical manipulations of the uterus including: dilatation of the cervix and curettage $(\mathrm{D} / \mathrm{C})$ of the uterus, therapeutic abortion, carcinoma of the cervix, or carcinoma of the endometrium, trophoblastic diseases, as well as other direct types of trauma to the uterus as well as AVMUs tend to occur more often in women who are within their reproductive ages [5]. It has been documented that the typical symptom of AVMU has tended to be bleeding from the vagina; nevertheless, some patients could manifest with lifethreatening massive bleeding. [1]. In view of the rarity of AVMUs, it would be envisaged that some clinicians globally may not encounter a case of AVMU in their working life and they would therefore tend not to be familiar with the diagnostic features and management of AVMUs. There is also the possibility that in areas of the world where facilities for the diagnosis of AVMUs are not available, patients who manifest with symptoms of AVMU could undergo hysterectomy in cases of uncontrollable vaginal bleeding from AVMU. Previously, hysterectomy had been the standard effective treatment to stop uncontrollable bleeding from AVMUs and the diagnosis was obtained upon histopathology examination of the hysterectomy specimens. Pursuant to developments in radiology diagnostic facilities and in interventional radiology, sporadic cases of successful treatments of AVMUs have been reported with the undertaking of less invasive procedures, one of which is selective angiography and super-selective embolization of arterial branching vessels that supply the AVM. We report a case of a bleeding AVMU which has been treated successfully by the undertaking of selective angiography and super-selective embolization of the AVMU and thus avoiding the undertaking of hysterectomy.

\section{Aims}

To report a case of arteriovenous malformations of the uterus and to review some cases of AVMU that had been previously treated.

\section{Method}

The Clinical Data System (Cerner) and the PACS system (Synapse) were utilized to obtain the details of the manifestation, the clinical examination findings, the radiology imaging records, the management and outcome of the individual in order to write the case report. Various internet search
Engines were searched including google, google scholar, yahoo, and PUBMED to obtain information related to arteriovenous malformations of the uterus in order to ascertain and review the literature on arteriovenous malformations of the uterus. The search words that were used included: arteriovenous malformations of the uterus, arteriovenous fistula of the uterus, uterine arteriovenous malformation, uterine arteriovenous fistula; congenital arteriovenous fistula of the uterus, and acquired arteriovenous fistula of the uterus. Twenty three references were identified which were used to write relevant aspects of the article.

\section{Results}

\section{(A) Case report}

A 27-year-old woman. Gravida 1. Para 0, who was known to have irregular menstrual periods, presented to the emergency department (ED) of Women's Wellness and Research Centre (WWRC) complaining of vaginal bleeding for a period of more than one month duration pursuant to her per vaginal passage of conception products. At the time of her miscarriage her expected gestational age was of around 14 weeks. She had ultrasound scan of abdomen and pelvis which showed features of retained products of conception. She was discharged home on Methylergonovine and antibiotics and to be followed-up after two weeks with a repeat ultrasound scanning. Two weeks later the patient reported that she had been having frequent heavy vaginal bleeding. She denied trauma, abdominal pain, nausea, or vomiting. The review of systems was otherwise normal. Her vital signs that were recorded within the emergency department (ED) included: a temperature of $36.5^{\circ} \mathrm{C}$, blood pressure of $110 / 64 \mathrm{~mm} \mathrm{Hg}$, pulse rate of 66 beats/minute, respiratory rate of 20 breaths per minute, and pulse oximetry of $99 \%$ on room air. Her general examination was unremarkable and her abdominal examination revealed a nondistended abdomen with no evidence of tenderness. Upon speculum examination there was scanty vaginal bleeding with normal closed cervical os. Her physical examination was otherwise unremarkable. The results of her laboratory investigations revealed negative urine pregnancy test, normocytic anaemia with a haemoglobin of $11.3 \mathrm{gm} / \mathrm{dL}$ and normal coagulation studies. She had transvaginal ultrasound scan which showed a well-defined tortuous vascular structure within her endometrium which was communicating with the prominent myometrium vessels (see Figures. A-1 and A-2). She had Colour Doppler ultrasound scan which showed a low resistive index and moderate velocity (see Figures. A-3 and A-4). The ultrasound scan features suggested the possibility of either vascular retained product of conception or arteriovenous malformation. 


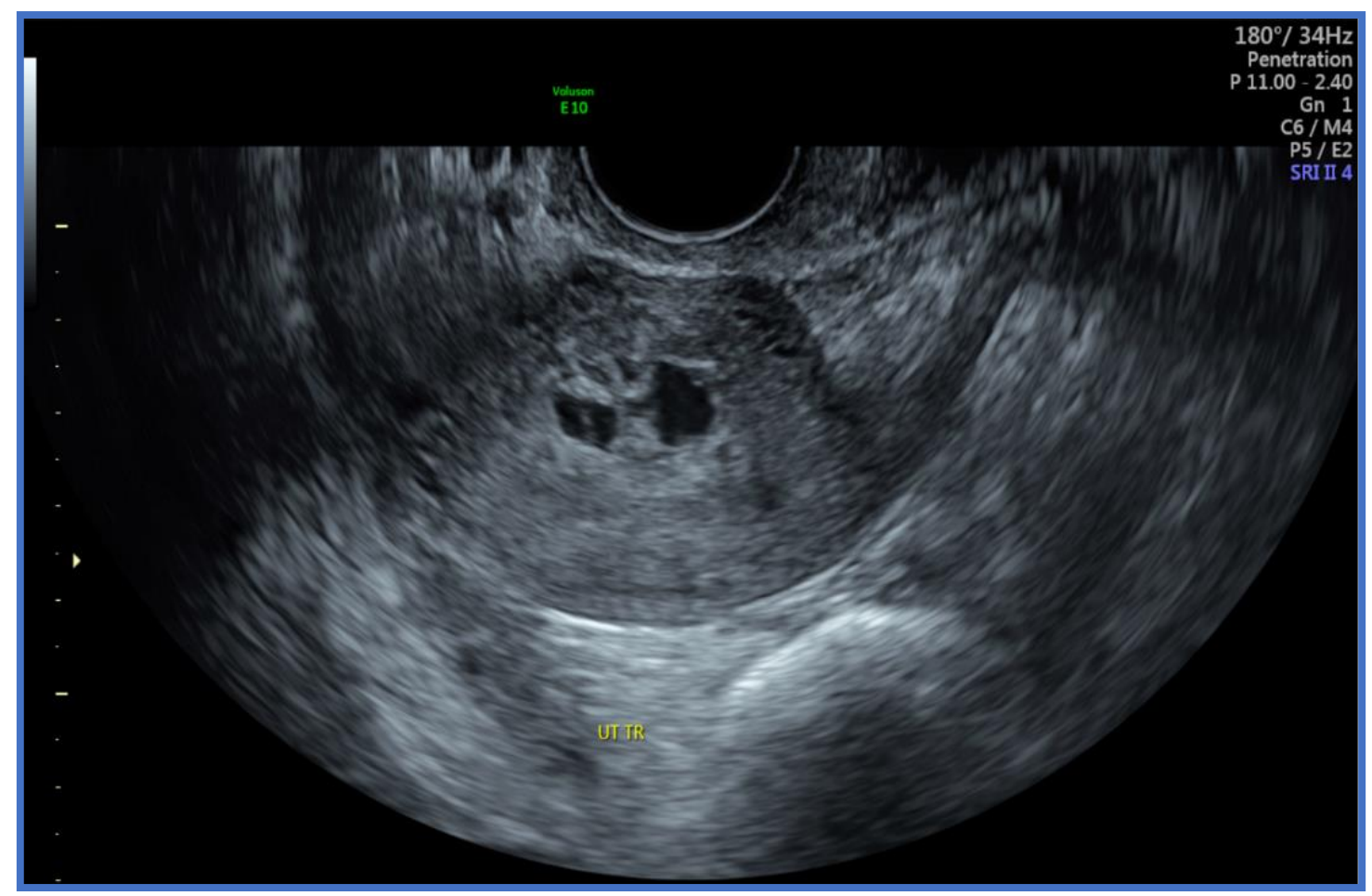

Figure A- 1 Transvaginal ultrasound showing a well-defined tortuous vascular structure in the endometrium communicating with the prominent myometrial vessels.

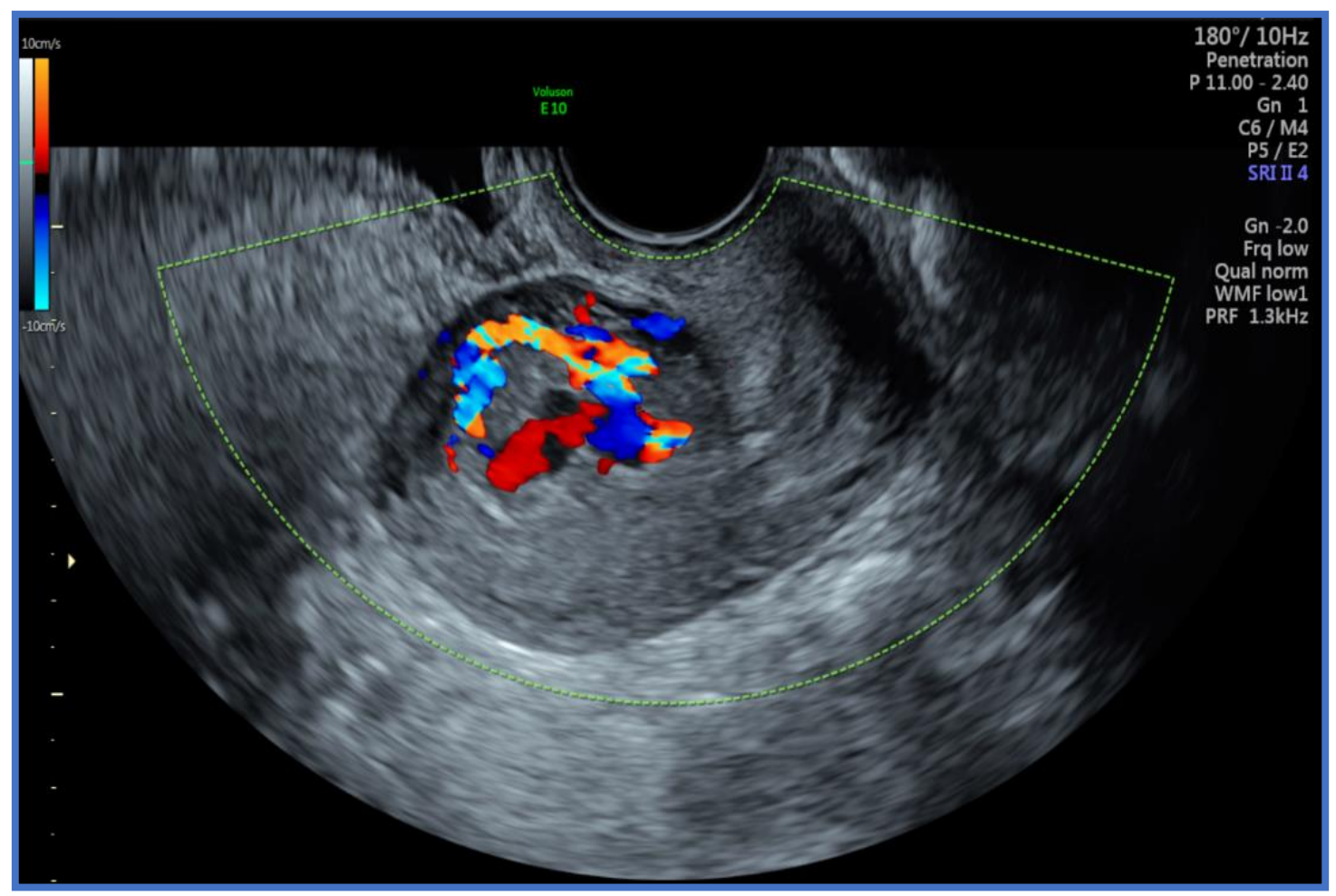

Figure A- 2 Transvaginal ultrasound showing a well-defined tortuous vascular structure in the endometrium communicating with the prominent myometrial vessels. 


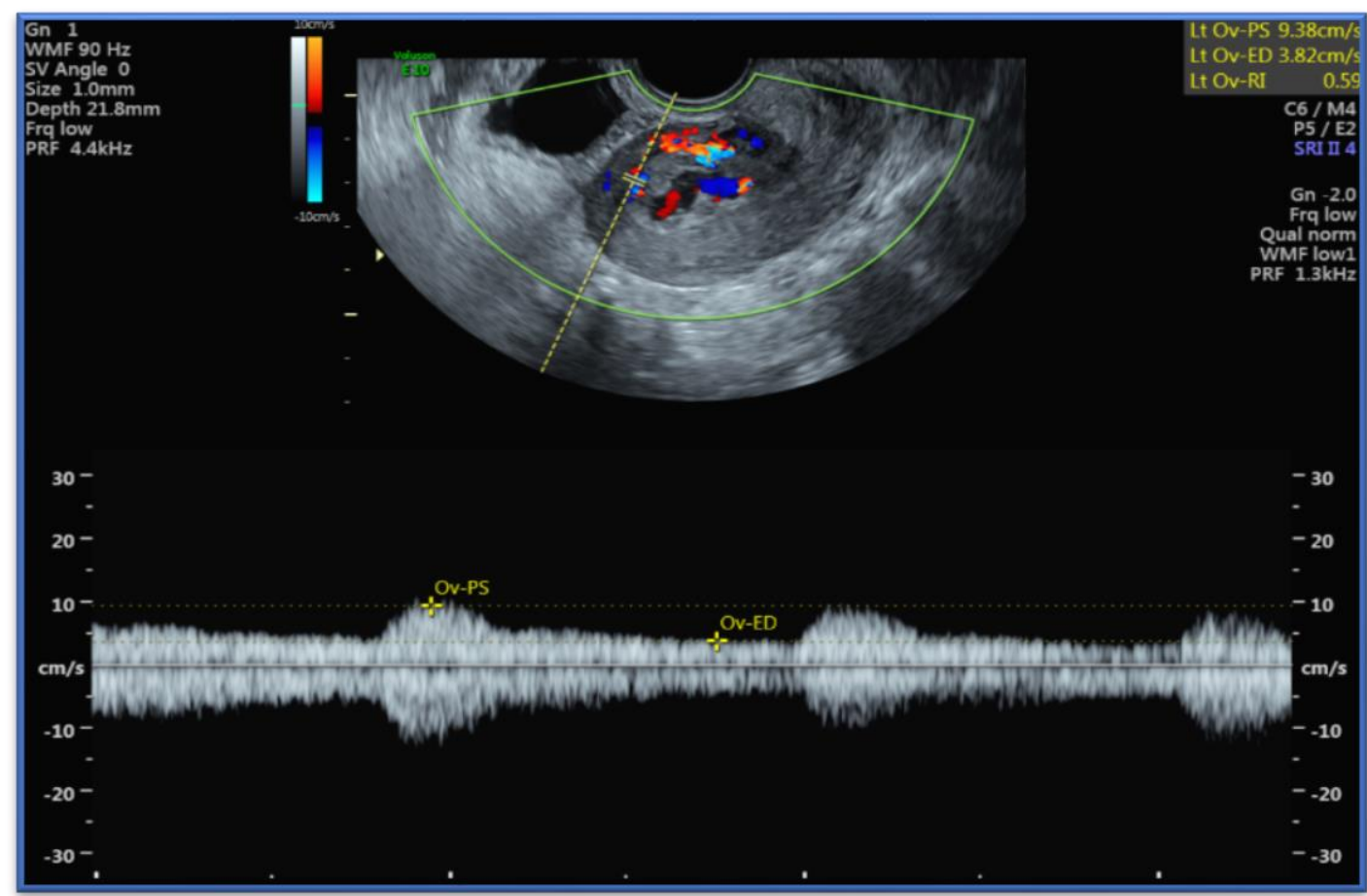

Figure A-3 Transvaginal ultrasound with doppler showing vascular lesion within the endometrium and extending to the myometrium having low RI and moderate velocity.

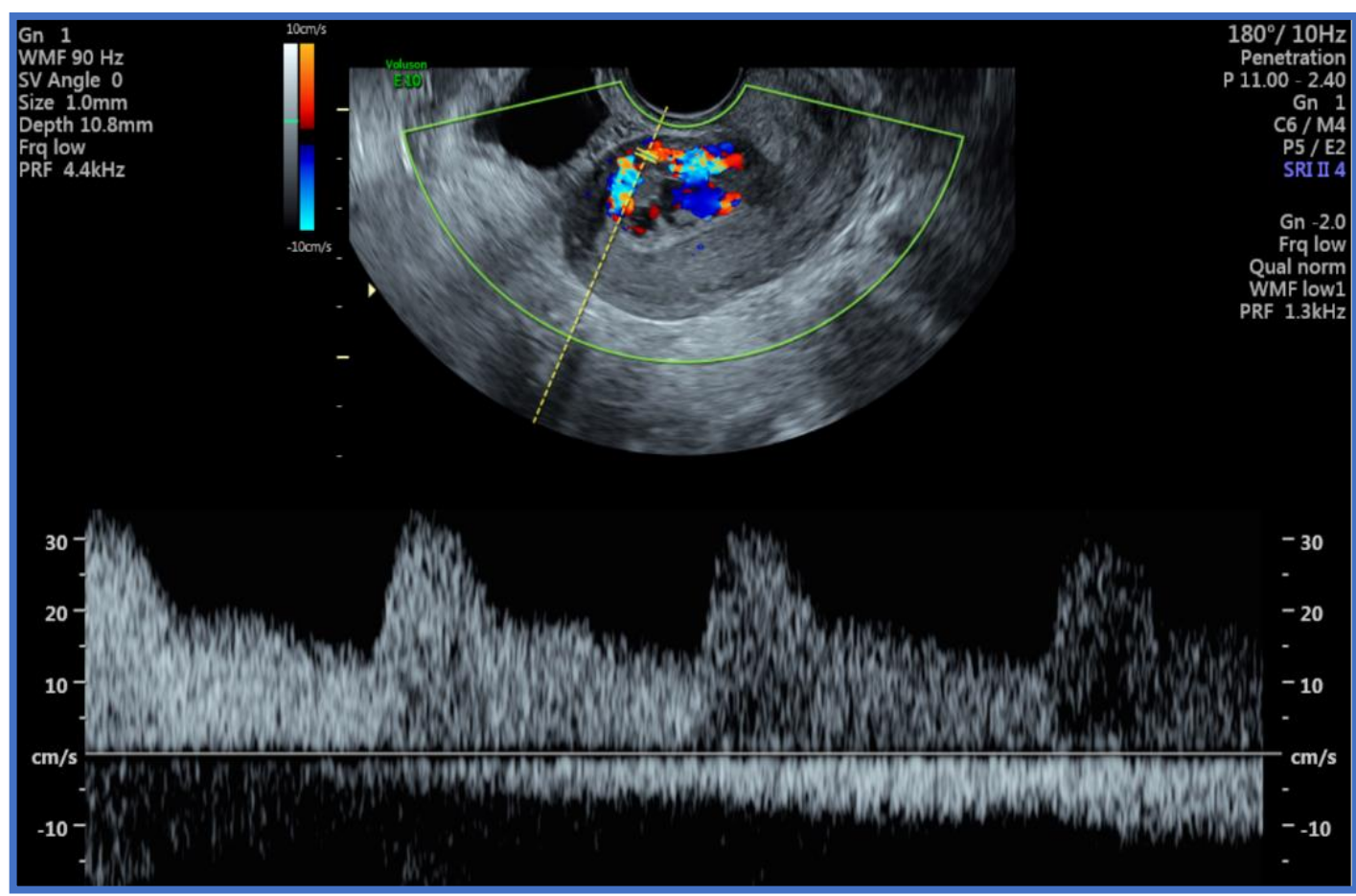

Figure A- 4 Transvaginal ultrasound with doppler showing vascular lesion within the endometrium and extending to the myometrium having low RI and moderate velocity.

She was admitted to the WWRC for observation and in order to undertake further radiology investigation with the undertaking of magnetic resonance imaging (MRI) scan of her pelvis. She did have MRI scan of her pelvis on $16^{\text {th }}$ of February 2021, which demonstrated variable signal with areas of high signal intensity on the $\mathrm{T} 1$ weighted images that was suggestive of blood/haemorrhage. On the post-contrast arterial phase of the MRI scan was demonstrated a serpentine intrauterine vessels which had penetrated the myometrium especially the anterior portion and which was considered to be most likely communicating with the venous system (see Figure. B-1). The aforementioned findings were compatible with the diagnosis of arteriovenous malformation (AVM). 


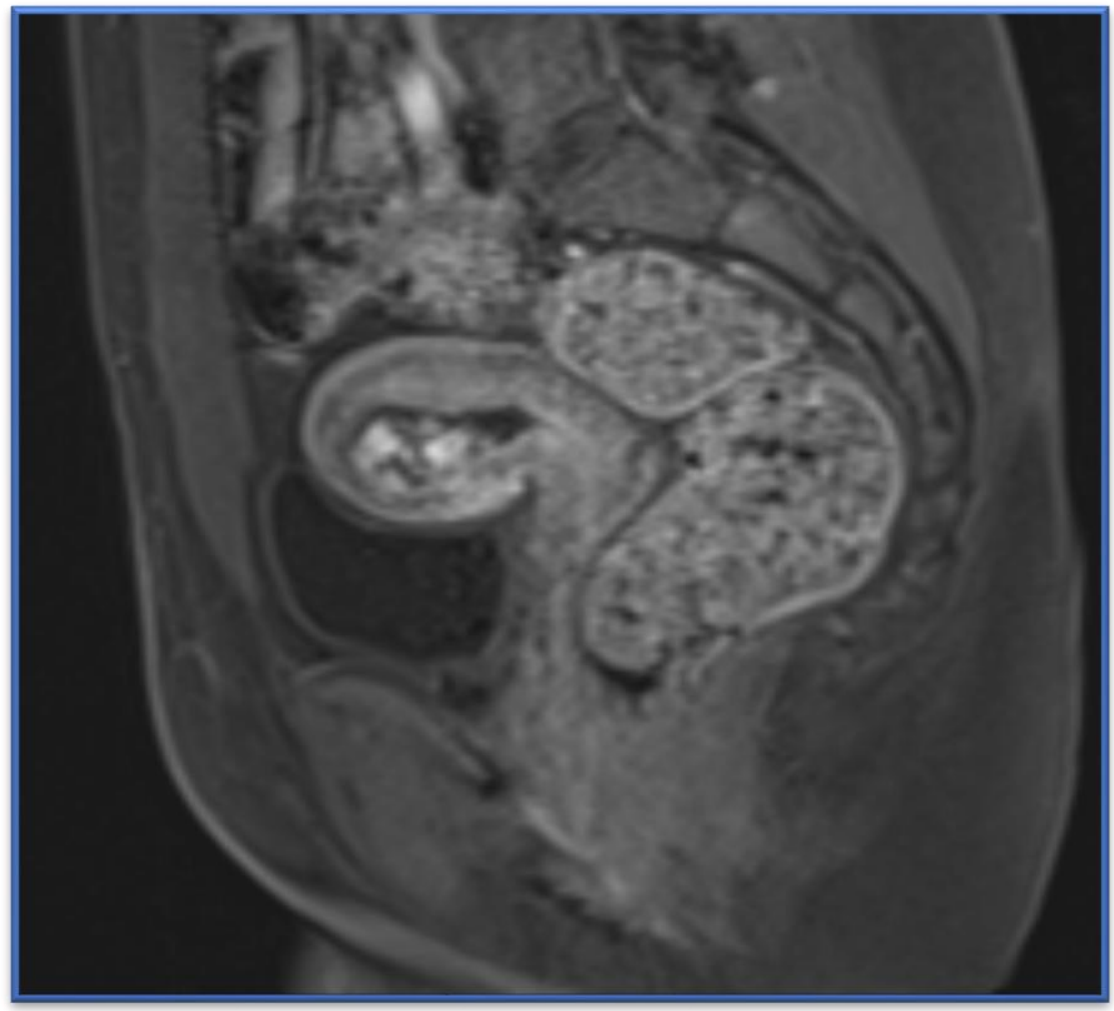

\section{Figure B-1 Post-contrast sagittal MRI pelvis showing Serpentine vessels penetrating the anterior myometrium.}

During her hospital stay she was doing well, she was vitally stable and she did not have any active vaginal bleeding or report any abdominal pain. Vascular surgery and Interventional radiology teams were consulted following which a multi-disciplinary team discussion was undertaken based upon which the final plan was to discharge the patient with an appointment scheduled for her on $22^{\text {nd }}$ February 2021 to undergo focused embolization of the arteriovenous malformation of the uterus (AVMU) by the Interventional radiologist as well as to undergo diagnostic hysteroscopy plus evacuation of the retained product of conception plus/minus laparoscopy, uterine balloon insertion and hysterectomy by

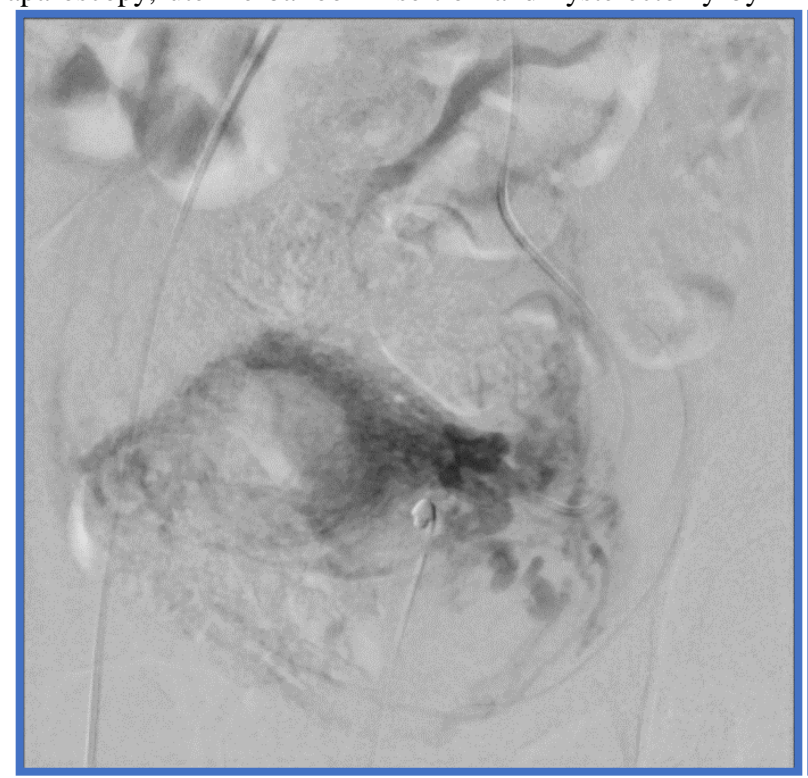

the obstetrics and gynaecology team. On the $22^{\text {nd }}$ of February 2021 the patient was admitted for percutaneous uterine arterio-venous malformation embolization by the Interventional radiology team. The procedure was undertaken under aseptic technique and local anaesthesia, angiogram of the left anterior internal iliac artery demonstrated arteriovenous (AV) malformation at the distal left uterine artery (see Figures C-1 and C-2). 500-700 particles were injected via micro catheter, the final angiogram showed satisfactory embolization result (see Figures C-3 and C-4).

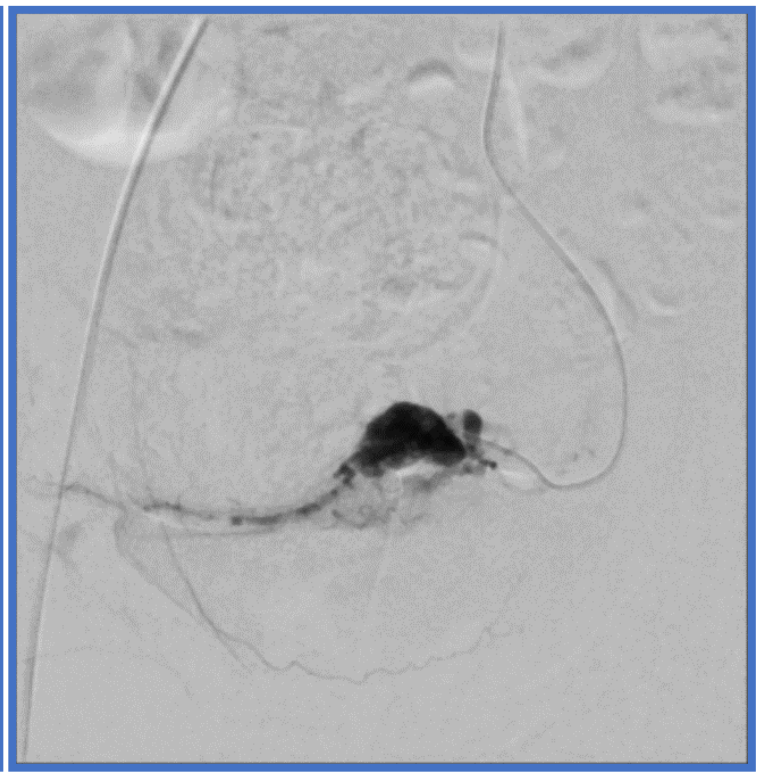



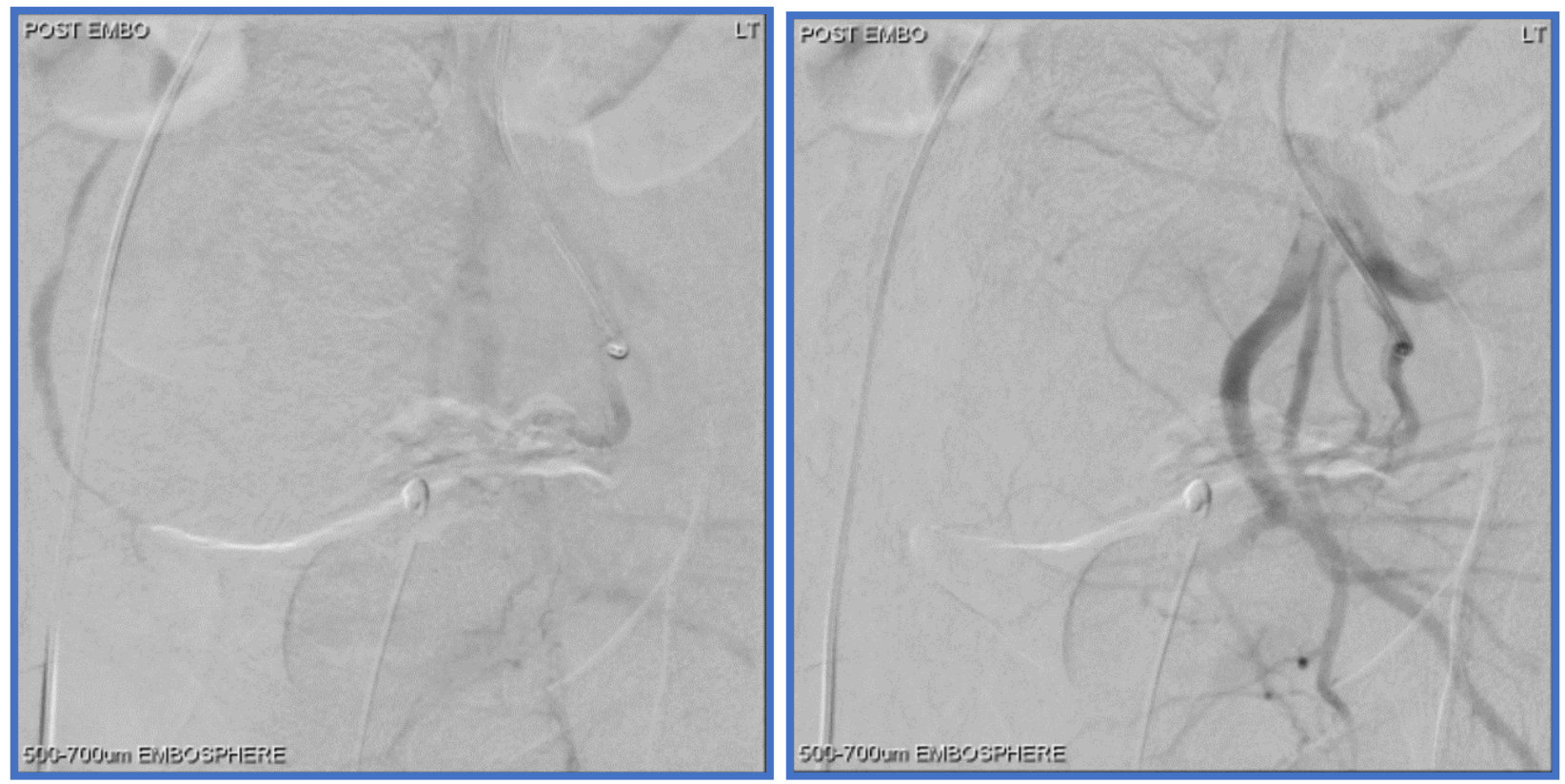

Figure C- 3 and C-4 Post-embolization angiogram is showing successful occlusion of the distal left uterine artery AVM.

Pursuant to the procedure she was doing well, and she did not develop any active bleeding or abdominal pain. The patient was discharged after 24 hours of observation on $24^{\text {th }}$ February 2021 with a follow up made for her to undergo magnetic resonance imaging (MRI) scan of her pelvis after one month and for her to be reviewed in the gynaecology clinic after four days from her discharge date. She was advised to seek medical help if she experienced vaginal bleeding or any red flag symptoms. On the $28^{\text {th }}$ of
February 2021 she was seen at the gynaecology clinic, she reported only lower abdominal discomfort with minimal infrequent vaginal bleeding, which was less in comparison with the bleeding she had experienced before the embolization. She had ultrasound scan of pelvis for follow up and this showed echogenic content that measured $2.9 \mathrm{~cm} \mathrm{x} 1.4 \mathrm{~cm}$ within the uterine cavity which could represent remnant or blood clots (see Figure. D-1).

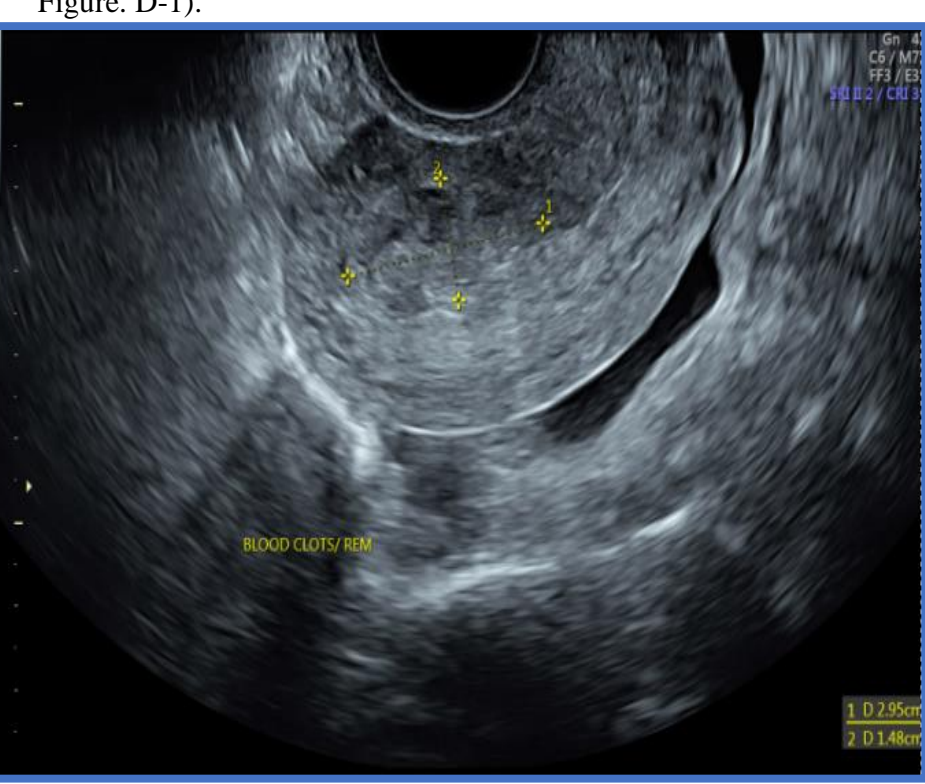

Figure D-1 Transvaginal ultrasound showing significant regression in the previously visualized AVM. And Figure D-2 showing remanent intrauterine echogenic structure.

She was admitted to the WWRC on $7^{\text {th }}$ March 2021 for termination of pregnancy by misoprostol as per incomplete miscarriage protocol after she had completed a full dose of misoprostol. She had ultrasound scan of pelvis for follow up on $9^{\text {th }}$ March, 2021 which demonstrated an echogenic non-vascular content within her uterine cavity that was consistent with a remnant of her product of conception or blood clot. On the $9^{\text {th }}$ of March
2021 the obstetrics and gynaecology team undertook diagnostic Hysteroscopy and Suction Evacuation of her retained product of conception under Ultrasound scan-guidance. Ultrasound scan of her pelvis was undertaken after the procedure and this showed successful complete evacuation of the retained product of her conception (see figures E-1 and E-2) 


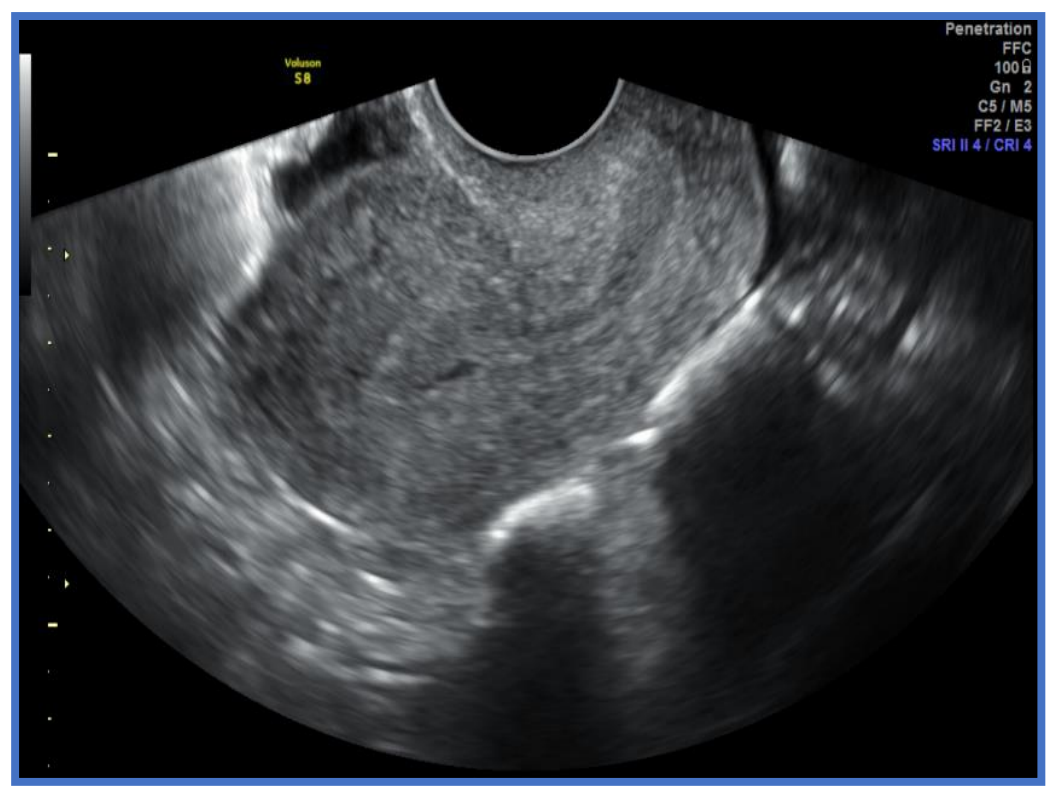

Figure E-1 Transvaginal ultrasound on post evacuation scan showing no remnants.

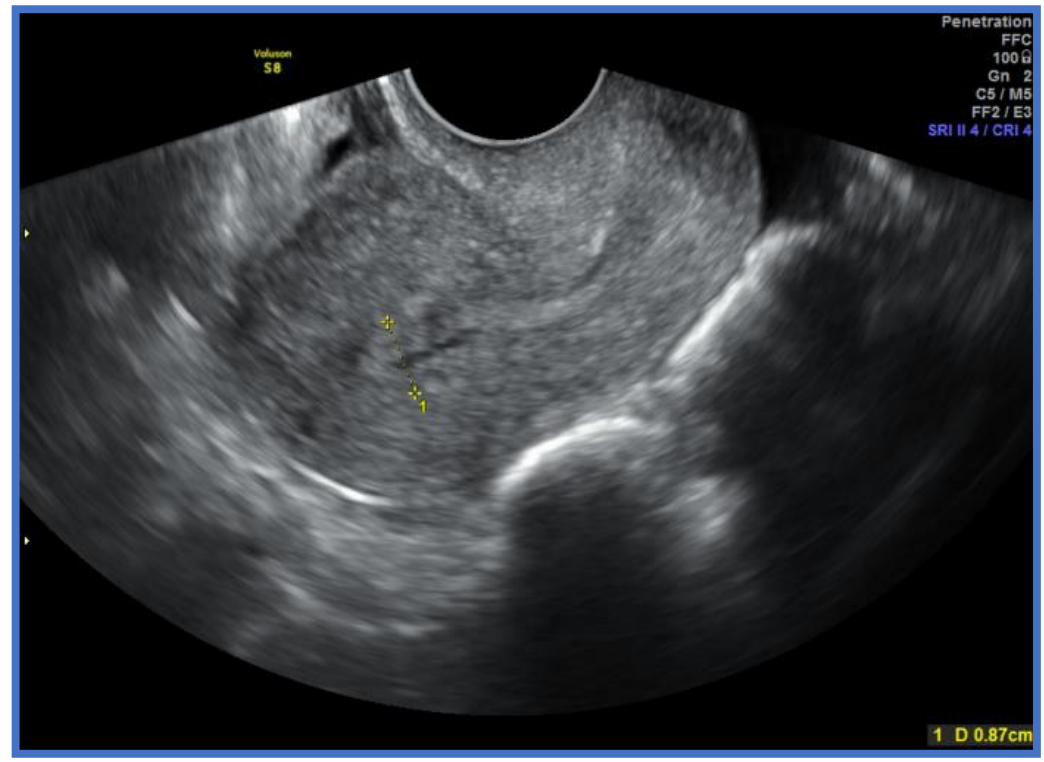

Figure E-2 Normal endometrial thickness of $8 \mathrm{~mm}$.

After the procedure she maintained stable vital signs with no complains, her laboratory investigation reported normocytic anaemia with normal coagulation profile. She was discharged on $10^{\text {th }}$ March 2021 on prophylactic antibiotic and with an appointment to be reviewed and assessed in the gynaecology clinic after 4 weeks. The specimen of her retained products of conception was sent to pathology laboratory for histopathology examination. On $16^{\text {th }}$ March 2021, the histopathology examination team reported that the pathology examination of the specimen demonstrated features of a scanty degenerated chorionic villi which was suggestive of products of conception.. She had magnetic resonance imaging (MRI) scan of the pelvis on the $29^{\text {th }}$ of March for follow up assessment pursuant to her AVM embolization, which demonstrated complete resolution of the previously documented uterine AVM. The MRI scan of her pelvis did not demonstrate any evidence of residual intrauterine soft tissue contents. The MRI scan of her pelvis showed that her endometrium measured about $5 \mathrm{~mm}$ in thickness and the endometrium exhibited normal signal intensity (see figure F-1). The post contrast MRI imaging did not show any abnormal vessels within the endometrium or in the myometrium which was indicative of successful post embolization response (see figure F-2). 


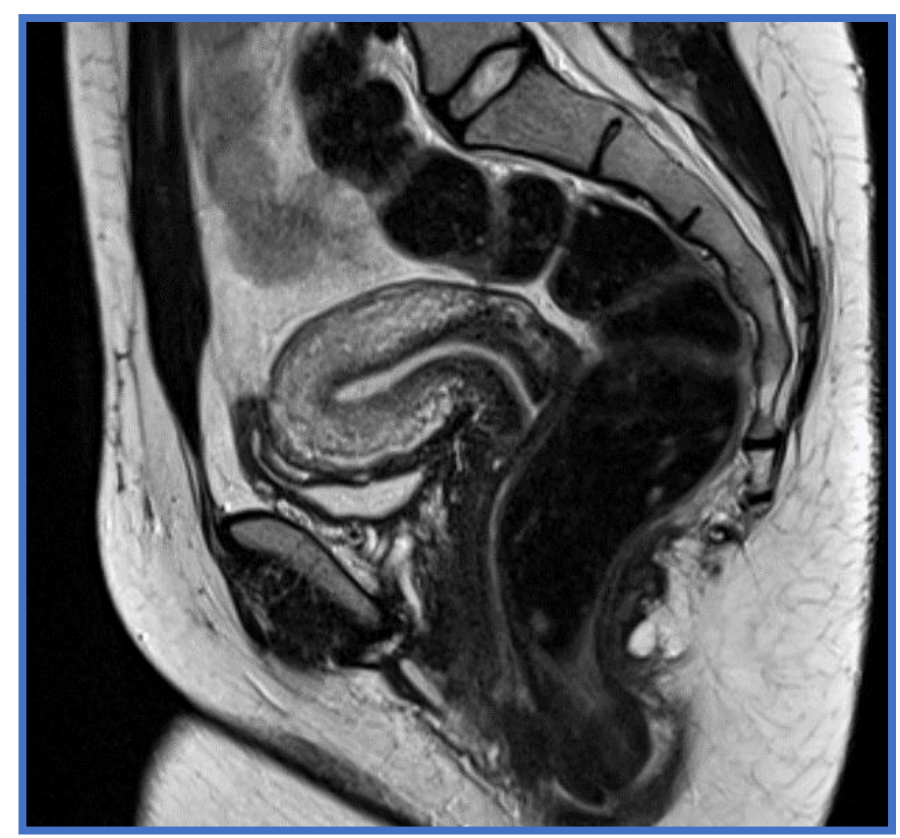

Figure F-1 MRI pelvis T2 weighted image sagittal plane showing normal signal intensity of the myometrium with endometrium thickness of 5 mm.

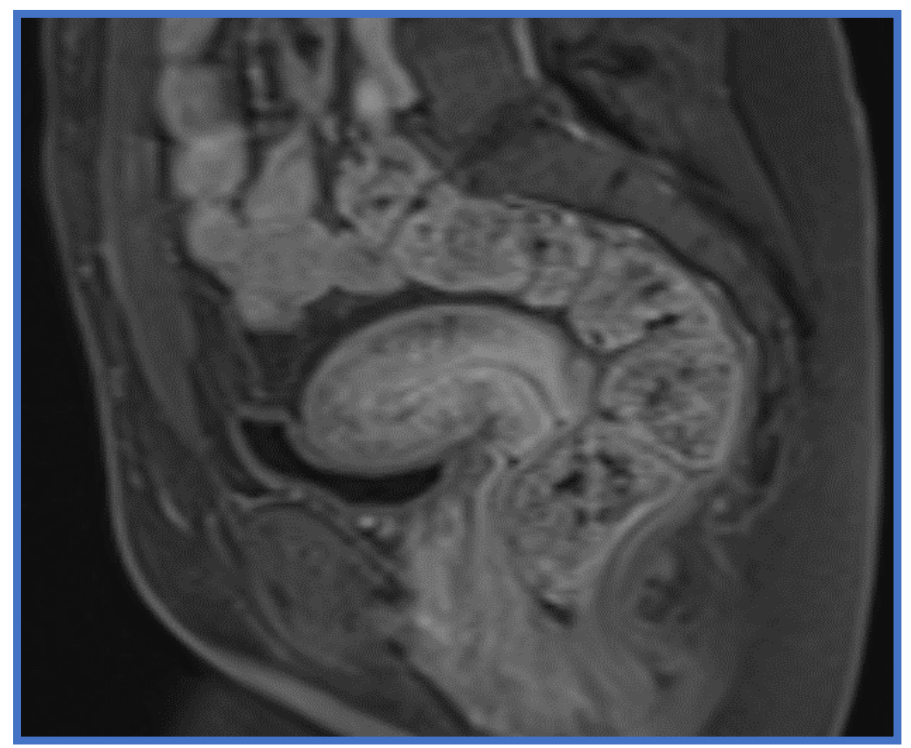

Figure F-2 MRI pelvis T1 weighted image post contrast sagittal plane showing no abnormal vessels within the endometrium.

\section{(B) Discussion and miscellaneous narrations and discussions from some case reports, case series and studies related to arteriovenous malformations of the uterus (AVMU).}

It has been iterated that AVMUs do have an important place with regard to the practice of gynaecology and obstetrics in view of the risk for the development of massive bleeding that could prove to be life-threating. [1] It has been iterated that congenital AVMUs have been postulated to arise from arrested vascular embryological development which does emanate in anomalous differentiation within the capillaries and abnormal communication, between arteries and veins. [6] It has also been iterated that congenital AVMUs could have multiple vascular connections which could invade encompassing structures. It is also pertinent to diagnose AVMU correctly, in order to commence appropriate and prompt treatment, in view of the fact that AVUMs often tend to cause lifethreatening massive and persistent bleeding from the vagina. [1] If facilities for the diagnosis of AVMU are not available in a health service establishment, an AVMU that is associated with persistent massive bleeding would be treated by hysterectomy and the opportunity uteruspreserving less-invasive treatment would be lost. It has been iterated that the management of AMU tends to be case based and this has tended to be mainly dependent upon the patient's clinical stability, age and desire for future pregnancies. Treatment AVMU does entail surgical removal [712].

Karadag et al [1]. iterated that the treatment of choice of AVMU does depend upon the symptoms of the patient, the age of the patient, the desire of the patient to be fertile in the future, as well as the localization and the size of the AVMU; nevertheless, embolization of the uterine artery branch supplying the AVMU is the first option of treatment regarding patients who have symptomatic AVMU during their reproductive ages and when they do have expectations of having future fertility. Karadag et al [1]. 
reported the case of an acquired AVMU pursuant to dilatation and curettage $(\mathrm{D} \& \mathrm{C})$ that was associated with an extensive AVMU lesion, that was successfully treated by means of bilateral uterine artery embolization (UAE) in order to maintain the fertility of a 35-year-old patient who was gravida 2, para 1, abortion 1, who had undergone D\&C at nine weeks as a result of missed abortion about two weeks preceding her manifestation in a different establishment and who was found to have a large AVMU. The undertaking of bilateral embolization of her uterine arteries did serve the purpose of maintaining her fertility.

Hashim and Nawawi [13] reported a 33-year-old lady who had manifested with secondary post-partum haemorrhage. She had trans-abdominal ultrasound scan of the pelvis which revealed increased vascularity with multi-directional flow of the uterus as well as a prominent vessel that was located upon the left lateral wall of her uterus. She also had retained products of conception which did complicate the diagnosis. A uterine artery angiography was undertaken which did confirm the diagnosis of AVMU within the fundal region of the uterus with an early draining vein. Embolization of the AVMU was successfully undertaken. The patient did express her desire to be pregnant again in the future. A lesson that has been learnt from this short case summation is the fact that the successful embolization of the AVMU has enabled her maintain her uterus with the hope of her becoming pregnant again.

Shintree and Coelho [14] reported a 27-year-old young nullipara female who had manifested with post-abortion bleeding that was caused by arteriovenous malformation of the uterus and retained products of conception. She had Doppler ultrasound scan of pelvis and magneticresonance imaging (MRI) scan of pelvis and the results of the two radiology imaging options were inconclusive about the exact nature of her uterine lesion. With uterine artery embolization facilities kept ready, evacuation of retained products of conception was undertaken with utmost care under ultrasound-scan guidance. Despite this, there was torrential life-threatening bleeding from her uterus and this was successfully tackled by the undertaking of uterine artery embolization that was associated with an added advantage of preserving the young lady's future fertility. Shintree and Coelho [14] stated that at the time of publication of their case report in 2017, less than 100 cases of arteriovenous malformations of the uterus had been published in the literature and these AVMs of the uterus can cause life-threatening torrential bleeding. They additionally, iterated that prompt diagnosis and treatment of AVMUs are necessary with the keeping of the differential diagnosis of retained products of conception and gestational trophoblastic disease in mind with regard to cases of post-pregnancy, post-abortion arteriovenous malformation.

Begum et al [15]. reported a 23-year-old lady, para 1, who had been having abnormal uterine bleeding for many months that was not responsive to conventional medical treatment option by means of hormonal treatment who was admitted because she had menorrhagia as well as severe anaemia. She did undergo vaginal delivery 7 years earlier. She did not have any past medical history of abortion or evacuation of uterus and curettage. Her menstrual cycle had been regular following menarche, at an interval of 28 days, and her bleeding does last for approximately 5 days. Over the preceding one year she had been suffering from menorrhagia and irregular menstrual cycles. She had received gynaecological treatment several times but her condition had not improved. She was admitted to hospital because of an abundant metrorrhagia with her haemoglobin level dropping to 4 grams per decilitre and upon her admission, she did receive blood transfusion to correct her anaemia. Her general examination on admission was normal except for her pallor and clinical examination features of severe anaemia. She had examination of her pelvis which demonstrated that her uterus was normal with regard to its size, and no abnormality was identified upon her palpation. Her vulva, vagina, and cervix were normal. She was normo- tensive and non-diabetic. The results of laboratory investigations including her thyroid function tests, coagulation profiles, and serum Beta Human Chorionic Gonadotrophin (B-HCG), were within their normal ranges. She had abdominal ultrasound scan which revealed normal sized uterus and her cervix was noted to be broad, as well as multiple grossly dilated engorged vessels and engorged vessels that were filled with blood were observed both in her cervix as well as in the body and fundus of her uterus upon Doppler ultrasound scan study which was highly indicative of arteriovenous malformation (AVM). The hospital establishment did not have facilities for the undertaking of interventional radiology pelvic angiography as well as embolization of her uterine artery. She was referred to a tertiary centre where facilities for interventional radiology were available; nevertheless, she was very poor and she could not afford to pay the expected expenses of the procedure so she refused to go to the tertiary centre. She therefore underwent a successful total hysterectomy in her local hospital. It would be argued that the patient underwent an effective and successful surgical treatment of hysterectomy to cure her bleeding problems at the expense of her future fertility. This problem would appear to be common in developing countries where facilities for interventional radiology are not easily available therefore in such countries and hospitals, some patients wo theoretically could be treated by minimal invasive treatment option of embolization of their uterine arteries cannot undergo such procedures. There is therefore the need for global efforts to be made to develop the training of more interventional radiologists and to provide more facilities for the development of interventional radiology services.

Jacques et al [16]. reported a 27-year-old nulli-gravid lady who was on warfarin anticoagulation because of the fact that she had a mechanical tricuspid valve and underlying congenital cardiac disease, who manifested with sudden onset of severe vaginal bleeding despite the fact that she had been taking oral contraceptives continuously. She had been admitted on three separate occasions over a period of 3 months for management of her menorrhagia and for which she ultimately required a total of 25 units of blood transfusion. She received high dose intravenous estrogen during her initial hospital admission which was successful and she was discharged home on oral contraceptive taper. Her vaginal bleeding had resumed many weeks later, and she manifested in the hospital where she had examination of her pelvis that demonstrated a bluish mass on the left of the apex of her vagina that was suspicious for an arteriovenous malformation (AVM). She was therefore re-admitted to hospital. She had magnetic resonance imaging (MRI) scan in view of her profuse vaginal bleeding and difficulty of controlling her vaginal bleeding by means of hormonal methods as well as the question of a pulsatile mass within her vagina that was found on her examination in order to assess her for an AVM. The MRI scan demonstrated blood products at various stages that expanded her endometrial cavity without any definite cause and no AVM was identified. She was taken to theatre for a dilatation and curettage and placement of intra-operative levonorgestrel intrauterine device. Pathology examination of the curettage specimen revealed features of a benign endometrium that had progestin effect. She was discharged home and did well but she expelled her IUD and she begun to bleed again. She was initially treated as an outpatient by placing an etonogestrel implant. She was subsequently re-admitted one week later because she had developed profuse bleeding from her vagina which did require blood transfusion. She was treated with utilization of depot leuprolide but this was not effective. Her INR was in the therapeutic range but this was reversed and following this she underwent laparoscopic hysterectomy and bilateral salpingectomy in view of failure of her many hormonal treatments as well as in view of the impact her vaginal bleeding was having on her cardiac function. Her uterus and pelvic anatomy during the operation looked normal and no evidence of an arteriovenous malformation was found. Histopathology examination of her uterus, cervix and fallopian tubes did were normal with no evidence of any abnormality. Her post-operative recovery was unremarkable and she was 
discharged home but 4 weeks after her operation, she re-manifested with acute vaginal bleeding and syncope. Her clinical examination demonstrated an intact vaginal cuff as well as profuse bleeding that necessitated utilization of wall suction for visualization. The vagina bleeding was observed at the right side of the vaginal cuff. Her vagina was then packed with gauze and she had CT angiogram of the pelvis which showed arterial bleeding within the right vaginal apex which looked concerning for arteriovenous malformation. She was transfused with two unts of packed red blood cells as well as her anticoagulation was reversed with utilization of pro-thrombin complex concentrate (PCC) and following this she underwent interventional angiography which showed active extravasation from her right uterine artery with an artery-to-venous fistula. Jacques et al. [16] stated the following:

- Arteriovenous malformations of the uterus are very uncommon entities and arteriovenous malformations that occur pursuant to hysterectomy are even more so very uncommon.

- $\quad$ Published cases of arteriovenous malformations that had developed or had been diagnosed pursuant to hysterectomy had reported symptoms from arteriovenous malformations 3 months to 35 years after the surgery [17-20].

- Their reported case was unique with regard to the short time interval from the procedure to the manifestation.

- Their reported case does serve as a reminder to clinicians to include arteriovenous malformation of the uterus as an uncommon cause of bleeding following hysterectomy and that uterine artery embolization could be considered as a successful treatment option even in close proximity to the initial surgical event.

Khan et al [10]. reported a 30-year-old G1P0010 lady who manifested with a six-day history of abnormal bleeding from her uterus. Three months preceding her manifestation, she did undergo therapeutic abortion which was ensued by dilatation and curettage (D\&C) to remove her retained products of conception. Pursuant to this she had been noted to have a new onset of menorrhagia, which on the day of her manifestation had become persistent and it was associated with severe pain, weakness, as well dizziness. Upon examination, she was noted to be hypotensive and to have tachycardia and to have marked tenderness within her supra-pubic region. Her examination was otherwise normal. The results of some of her laboratory investigations included: haemoglobin of 9.2 grams per decilitre, haematocrit $27.5 \%$, and Beta-Human Chorionic Gonadotrophin (Beta-HCG). She had trans-vaginal ultrasound scan which showed a 3.9 $\mathrm{cm} \times 2.7 \mathrm{~cm} \times 1.8 \mathrm{~cm}$ sized anechoic, cystic space within the posterior wall of the fundus of her uterus. She had Doppler ultrasound scan which showed marked vascularity. Her additionally contrast-enhanced magnetic resonance imaging (CE-MRI) scan to further assess the lesion which demonstrated a contrast-opacified structure within the wall of her myometrium. The CE-MRI scan also illustrated focal serpiginous flowvoids within the posterior-superior myometrium that had extended to the myometrium canal. The features of the radiology imaging options were interpreted as being consistent with the diagnosis of arteriovenous malformation of the uterus. She underwent interventional radiology uterine angiogram which did confirm the diagnosis of arteriovenous malformation (AVM) within the posterior-superior wall. The angiography study also demonstrated multiple feeding arteries that were mainly from the left side with smaller arteries from the right side. Embolization of both the left and the right uterine arteries was undertaken with utilization of Gelfoam (Pfizer, New York, USA) pledgets to near stasis. At the end of the procedure, a post-embolization arteriogram was undertaken which demonstrated complete embolization of the arteriovenous malformation (AVM) and slow flow of contrast within both the left and right uterine arteries. The embolization procedure was undertaken uneventfully. Her vaginal bleeding resolved pursuant to the embolization and she was discharged 3 days subsequently. She did not report any recurrence of abnormal uterine bleeding at her 3-months- and 6-months follow-up assessment.

Khan et al. [10] made the ensuing summations related to AVMUs:

- Even though AVMUs represent an uncommon cause of abnormal bleeding from the uterus, with the increased undertaking of surgical gynaecology work, the prevalence of acquired AVMUs would most likely increase.

- It should therefore be realised that AVMU is an important differential diagnosis which should be taken into consideration with regard to any patient who manifests with abnormal uterine bleeding.

- It has been iterated that the first case of AVM was described in 1926 and up to the time of the report of their case of AVMU in 2019, less than 100 cases of AVMU had been reported in the literature [21,22].

- With regard to their reported case, a dilatation and curettage (D\&C) was considered to be the likely the inciting event that emanated in the formation of the acquired AVM of the uterus.

- It has been documented that acquired AVMUs could also be associated with the undertaking of caesarean section, pelvic surgery, infection, gestational trophoblastic disease, and some gynaecology malignancies [13].

- Previously, it was difficult to diagnose AVMUs and AVMU was often diagnosed based upon tissue histopathology examination pursuant to the undertaking of hysterectomy.

- It has been documented that the availability of Colour Doppler ultrasound scan has transformed the diagnosis of AVMU [23].

- Which currently is a non-invasive modality which could help with regard to the detection of this uncommon condition [6].

- It has been iterated that a confirmatory test often tends to be followed in view of the fact that products of gestation, haemangioma, gestational trophoblastic disease, as well as complex cysts of the ovary could depict a hyper-vascular appearance that is associated with a turbulent flow upon Doppler ultrasound scanning [13]. In view of this digital subtraction angiography does remain the goldstandard diagnostic radiology imaging option to confirm the diagnosis of AVMU [5].

- It has been stated that the traditional preferred option of treatment for AVMUs has been hysterectomy; nevertheless, uterine artery embolization (UAE) is increasingly becoming one of the preferred treatment options based upon the facts that include: its effectiveness, minimally invasive nature of the procedure, and the possibility of the procedure enabling the preservation of uterine function which does allow for future pregnancy/child bearing [11].

- It has been iterated that studies had illustrated that the undertaking of bilateral uterine artery embolization (BUAE) tends to be ninety percent $(90 \%)$ effective and that the technical failures having been attributed to complications of the procedure, incomplete embolization, and rupture of the uterine artery [9].

- It has been documented that a variety of embolic materials had been utilized in the treatment of AVMU including: polyvinyl alcohol, histoacryl glue, stainless steel coils, detachable balloons, and haemostatic gelatine; [13] nevertheless, there has so far not been any study that has compared the efficacy between the different methods / embolic materials. 
- With regard to their reported case, they had utilized Gelfoam pledgets successfully embolize the AVMU without the development of any complication or the need to undertake re-embolization.

- Their reported case has highlighted both the diagnostic advances in the identification of AVMUs as well as it has demonstrated the effectiveness of utilization of Gelfoam pledgets as a single embolization agent for an urgent bilateral uterine artery embolization (UAE) in the treatment of AVMU.

Khan et al. [10] concluded that bilateral uterine artery embolization with utilization of Gelfoam pledgets is safe, effective, as well as it is a minimally invasive method that can be utilized to treat AVMUs with long-term efficacy which could provide the preservation of fertility.

Vilos et al. [11] stated that arteriovenous malformations of the uterus (AVMS) are uncommon and could be classified as either congenital or acquired and that acquired AVMS could emanate from trauma, instrumentation of the uterus, infection, or gestational trophoblastic disease. Vilos et al [11]. also iterated that most cases of acquired AVMS tend to be encountered in women of reproductive age who have a history of at least one pregnancy. Vilos et al. [11] also stated that the traditional treatment options for AVMs had included: medical management of symptomatic bleeding, blood transfusions, uterine artery embolization (UAE), or hysterectomy. Vilos et al. [11] reported the results of their retrospective study of their case series of five (5) symptomatic women who had AVM and UAE of reproductive age and who wished to preserve their fertility. With regard to the results, Vilos et al. [11] reported the following:

- The ages of the patients had ranged between 18 years and 32 years, and they had between 1 and 3 previous pregnancies preceding their initial manifestations.

- $\quad$ All of the patients were followed-up until they had their deliveries.

- $\quad$ All five patients did deliver live births (life babies).

- Three of the five patients did require two embolization procedures and one of these two ladies did require a subsequent hysterectomy.

- Two out of the five $(40 \%)$ deliveries were at term and they had normal weight babies as well as normal placenta.

- One woman out of the five women that amounted to $20 \%$ had cerclage placed and she developed chorioamnionitis at 34 weeks but she had a normal placenta.

- Two pregnancies out of the five pregnancies that amounted to $40 \%$ were induced at less than 37 weeks of gestation for pre-eclampsia/b intrauterine growth restriction +/- abnormal umbilical artery dopplers. The low birth weight were both less than 2000 grams. Both placentas did show accelerated maturity infarcts.

- All estimated blood losses were recorded as less than 500 cubic centimetres.

Vilos et al. [11] concluded that uterine artery embolization (UAE) may not be as effective at managing arteriovenous malformation of the uterus (AVMU) as was previously thought and UAE should be questioned as an initial treatment in symptomatic women of reproductive age who desire preservation of their fertility. Despite the conclusion of Vilos et al. [11] the fact that all five patients managed to deliver a baby following UAE of their AVMUs the procedure is fairly safe and effective had enabled all the women to deliver a baby each and unless an alternative treatment option is found through a multi-centre trial that is associated with better results, then uterine artery embolization should continue to be offered to women with AVMU who want to maintain their fertility and to deliver future babies.

\section{Conclusions}

- Various radiology imaging options are available that enable clinicians to diagnose AVMUs including ultrasound scan, contrastenhanced computed tomography (CE-CT) scan, contrast-enhancing magnetic resonance imaging (CE-CT) scan, and interventional radiology angiography but the gold standard confirmatory diagnostic radiology imaging option that is so far available is digital subtraction angiography which also has the additional advantage of enabling embolization that serves the purpose of treatment as well.

- Even though hysterectomy has traditionally been undertaken in the management of individuals who have severe bleeding from AVMU, it does have the disadvantage of being more invasive and does require General anaesthesia or spinal anaesthesia as well as it is associated with loss of preservation of fertility. Nevertheless if less invasive methods of treatment including UAE fail then hysterectomy either by the open method or laparoscopy method can be undertaken.

- The outcome of our anecdotal case has confirmed the findings of other clinicians that UAE as treatment of AVMU is a safe and effective option of treatment that should be offered to all stable individuals that have bleeding AVMUs in the first instance in comparison with hysterectomy because it is safe, effective, and minimally invasive. Hysterectomy should be reserved for cases in which UAE does fail.

- There is information that shows that UAE is also effective for the treatment of bleeding AVMs that are diagnosed or develop pursuant to hysterectomy.

- Considering that there are many embolization agents for the treatment of AVMU, there is an urgent need for a global multi-centre trial that compares the various treatment agents in order to ascertain the best embolizing agents that should be utilized or to confirm that all the embolization agents are equally effective.

- Interventional radiology does have a crucial role to play in the treatment of stable patients who have AVMU by providing a minimally invasive obliteration of the uterine arteries and thus depriving the AVMU of blood supply which does stop bleeding from the AVMU. .

- The associated complication of embolization of the AVMU tend to be rare events and these complications tend to be vary depending upon the type of occlusive material that is utilized and it is worth noting that are many possible materials that can be utilized for embolization of AVMU.

- Considering that there are not many interventional radiologists in all parts of the world including the fact that there are not many interventional radiology facilities in most parts of the developing countries, there is the need to train more interventional radiologists globally and to establish more interventional radiology units though out the world so that every radiology department would have facilities for interventional radiology as well as a well-trained interventional radiologist.

\section{Conflict of interest}

None (We do not have any conflict of interest to declare).

\section{Acknowledgements}

Acknowledgements to: 
- The patient for granting us permission to report her case if lessons learnt from her management could be of future benefit to clinicians in the management of patients whose cases would be similar to her case.

- The Interventional Radiology Team of the Department of Radiology, Hamad Medical Corporation, Doha, Qatar and the Department of Radiology, Hamad Medical Corporation, Doha, Qatar, for their support.

\section{References}

1. Koradag B, Erol O, Ozdemir O, Uysal A, Alparslan A S, Gurces C, Koroaglu M. (2016) Successful Treatment of Uterine Arteriovenous Malformation due to Uterine Trauma. Case Reports in Obstetrics and Gynecology; Volume 2016; Article ID: 1890650: 3 pages.

2. O'Brien P, Neyastani A, Buckley A R, Chang S D, Legiehn G M. (2006) Uterine arteriovenous malformations: From diagnosis to treatment. Journal of Ultrasound Medicine; 25(11): 1387-1392.

3. Halperin R, Schneider D, Maymon R, Peer A, Pansky M, Herman A. (2007) Arteriovenous malformation after uterine curettage: a report of 3 cases. J Reprod Med; 52(5):445-9.

4. Cura M, Martinez N, Cura A, Dalsaso TJ, Elmerhi F. (2009) Arteriovenous malformations of the uterus. Acta Radiol. Sep; 50(7):823-9.

5. Grivell RM, Reid KM, Mellor A. (2005) Uterine arteriovenous malformations: a review of the current literature. Obstet Gynecol Surv;60(11):761-7.

6. Polat P, Suma S, Kantarcý M, Alper F, Levent A. (2002) Color Doppler US in the evaluation of uterine vascular abnormalities. Radiographics; 22(1):47-53.

7. Nikolopoulos G, Murray A. (2004) Successful pregnancy outcome after surgical removal of arteriovenous malformation of the uterus. J Obstet. Gynaecol. 24(3):315-6.

8. Wu Y C, Liu W M, Yuan C C, Ng H T. (2001) Successful treatment of symptomatic arteriovenous malformation of the uterus using laparoscopic bipolar coagulation of uterine vessels. Fertil Steril. 76(6):1270-271.

9. Kim T, Shin JH, Kim J, Yoon HK, Ko GY, Gwon DI, Yang H, Sung KB. (2014) Management of bleeding uterine arteriovenous malformation with bilateral uterine artery embolization. Yonsei Med J; 55(2):367-73.

10. Khan S, Saud S, Khan I, Achakzai B. (2019) Acquired Uterine Arteriovenous Malformation Following Dilatation and Curettage Treated with Bilateral Uterine Artery Embolization: A Case Report. Cureus. 11(3):e4250.
11. Vilos AG, Vilos GA, Hollett-Caines J, Rajakumar C, Garvin G, Kozak R. Uterine artery embolization for uterine arteriovenous malformation in five women desiring fertility: pregnancy outcomes. Hum Reprod. 30(7):1599-605.

12. Yokomine D, Yoshinaga M, Baba Y, Matsuo T, Iguro Y, Nakajo M, Douchi T. (2009) Successful management of uterine arteriovenous malformation by ligation of feeding artery after unsuccessful uterine artery embolization. J Obstet. Gynaecol. Res. Feb; 35(1):183-8.

13. Hashim H, Nawawi O. (2013) uterine arteriovenous malformation. Malays J Med Sci ; 20(2):76-80.

14. Shintree H, Coelho K S. (2017) Managing Uterine Arteriovenous Malformation (AVM) Is Like Dealing With Raging Wildfire Awaiting a Spark: Better Be Extremely Cautious \& Be Ready With Countermeasures Like Uterine Artery Embolization (UAE). Obstet Gynecol Int; 6(1): 00195.

15. Begum M, M Begum, Sultana S, Hossain M A, Quddus M. (2018) Arteriovenous Malformation Of The Uterus. IOSR Journal of Pharmacy. 8(1): 44 - 46

16. Jacques L, Lund M, Baruah D. (2016) Uterine Arteriovenous Malformations: A Rare Cause of Vaginal Hemorrhage after Hysterectomy. Gynecol Obstet Case Rep, 2:2. doi:10.21767/24718165.1000029.

17. Smith Michael R Pulsatile pelvic masses: (1995) Options for evaluation and management of pelvic arteriovenous malformation. Am J Obstet Gynecol; 1857-1863.

18. Sharma A. (2009) Vogelzang R L Uterine arteriovenous fistula as a long-term complication of hysterectomy. Obstet Gynecol; 113: 489-491.

19. Fulmer G T, Mayberger H W, Sheehy T J, Hayden C W Arteriovenous fistula of the uterine artery. (1970) A rare complication of hysterectomy. Angiology; 21: 647-653.

20. Badawy SZ, Etman A, Singh M, Murphy K, Mayelli T (2001) Uterine artery embolization. The role in obstetrics and gynaecology. J clin imaging ; 25: 288-295.

21. Fleming H, Ostör AG, Pickel H, Fortune DW. (1989) Arteriovenous malformations of the uterus. Obstet Gynecol. 73(2):209-14.

22. Hickey M, Fraser IS. (2000) Clinical implications of disturbances of uterine vascular morphology and function. Baillieres Best Pract Res Clin Obstet Gynaecol. 14(6):937-51.

23. Timor-Tritsch IE, Haynes MC, Monteagudo A, Khatib N, Kovács S. (2016) Ultrasound diagnosis and management of acquired uterine enhanced myometrial vascularity/arteriovenous malformations. Am J Obstet Gynecol. 214(6):731.e1-731.e10.
This work is licensed under Creative Commons Attribution 4.0 License

To Submit Your Article Click Here: Submit Manuscript

DOI: $10.31579 / 2693-4779 / 050$

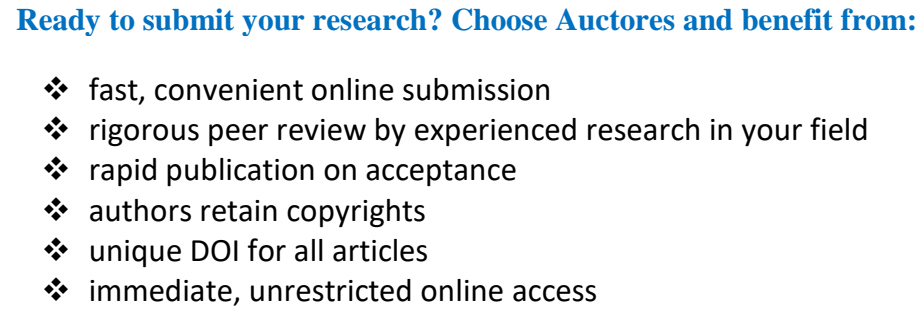

Ready to submit your research? Choose Auctores and benefit from:

* fast, convenient online submission

* rigorous peer review by experienced research in your field

* rapid publication on acceptance

* authors retain copyrights

* unique DOI for all articles

* immediate, unrestricted online access

At Auctores, research is always in progress.

Learn more www.auctoresonline.org/journals/clinical-research-andclinical-trials 